\title{
ИНДИКАТОРЫ ЦИФРОВОГО ОБРАЗОВАНИЯ СЛУЖБ ИНФОРМАТИЗАЦИИ УНИВЕРСИТЕТА
}

\section{DIGITAL EDUCATION INDICATORS OF UNIVERSITY INFORMATIZATION SERVICES}

V. Azarov

Summary. Currently, there is not a sufficient number of scientific works and publications on the assessment of digital education and ICT tools in the corporate network environment of universities. University quality management systems and local indicators may not fully reflect the variety of processes taking place on digital education platforms. The categories of saturation with computers with access to the Internet, the amount of applied and instrumental software are not always sufficient for understanding and assessing promising capital investments and building a progressive plan for the financial and economic activities of the university. In this regard, the work on the description of the methodological connection between the digitalization processes, qualimetric assessments, and the formation of recommendations for planning the ICT budget is relevant. The developed indicators are indicators of the formation of the network telecommunications infrastructure, digital services, educational IT resources, means of protecting digital resources. The paper talks about belonging to the departments of informatization: the departments of the vice-rector for information technology, the educational and methodological department, the scientific library, the institute of continuing professional education and a separate component of the information security of the information and telecommunications infrastructure of the university. Arguments are given for the inclusion of services in the list of departments that form the digital environment of the university. As an example, the functional and semantic definitions of individual indicators are described, the results of assessing indicators by statistical methods are considered. The conclusion is made about the possibility of applying the approach to assessment to create a billing system for assessing the quality of education and blitz testing of state IT systems.

Keywords: universities, informatization services, digital education indicators, statistical methods.

\author{
Азаров Вячеслав Геннадьевич \\ К.т.н., дочент, Арктический государственный \\ агротехнологический университет \\ west_55@inbox.ru)
}

Аннотация. В настоящее время отсутствует достаточное количество научных работ и публикаций по оценке цифрового образования и средств ИКТ в корпоративной сетевой среде университетов. Системы менеджмента качества университета и локальные показатели не в полной мере могут отражать многообразие процессов, происходящих на платформах цифрового образования. Категории насыщенности вычислительной техникой с доступом к Internet, количество прикладного и инструментального программного обеспечения не всегда достаточны для понимания и оценки перспективных капиталовложений и построения прогрессивного плана финансово-хозяйственной деятельности университета. В этой связи актуальными являются работы по описанию методологической связи между процессами цифровизации, квалиметрическими оценками, формирования рекомендаций для планирования бюджета ИКТ. Разработанные индикаторы представляют собой показатели сформированности сетевой телекоммуникационной инфраструктуры, цифровых сервисов, образовательных ІТ-ресурсов, средств защиты цифровых ресурсов. В работе говорится о принадлежности к подразделениям информатизации: подразделений проректора по информационным технологиям, учебно-методического отдела, научной библиотеки, института непрерывного профессионального образования и отдельно выделенной компоненте информационной безопасности информационно-телекоммуникационной инфраструктуры университета. Приводятся аргументы для включения служб в список подразделений, формирующих цифровую среду университета. В качестве примера, описаны функционально смысловые определения отдельных индикаторов, рассмотрены результаты оценки индикаторов статистическими методами. Сделан вывод о возможности применения подхода к оценке для создания биллинговой системы оценки качества образования и блиц проверке государственных ІТ систем.

Ключевые слова: высшая школа, службы информатизации, индикаторы цифрового образования, статистические методы.

\section{Ввеление}

4 елесообразность введения оценок, показателей и индикаторов в систему образования Российской Федерации заключается в необходимости сравнения количественных и качественных критериев с целью оптимизации системы образования, в случае кризиса, отставания или предотвращения угроз, связанных с разрывом между развитыми странами и странами третьего мира в научно-технических знаниях, уровне жизни, экономическом развитии. С точки зрения информатизации и современной «цифры», может использоваться ряд показателей, например, цифровые компетенции студентов, насыщенность вычислительной техникой, интеграция информационных ресурсов, доступность федеральных, региональных и муниципальных баз данных и цифровых технологий $[1,2,3]$. 
На уровне университета, индикаторы и группы индикаторов при достаточной глубине мониторинга могут быть полезны руководителям для принятия решений [4]. В работе [5] говорится о важности оценки деятельности университетов при помощи индикаторов, характеризующих качество выпуска специалистов с высшим образованием по направлениям, конгруэнтным профилю развития экономики региона, научно-исследовательской, патентной и публикационной активности и внедрение инновационных технологий в экономику региона и функционирование региональной инновационно-информационной инфраструктуры. Подобные подходы реализованы в США [6], Германии [7] и ряде других странах, и позволяют не только сформировать аналитическую отчетность и прогнозы развития образовательных территорий, но и получать государственные целевые инвестиции и поощрения.

Наиболее известными индикаторами образовательных систем являются, например, International Indicators of Education Systems (INES), индикаторы PISA, PIRLS, TIMSS, PIAAC и другие [8]. В части оценки информационных и цифровых компетенций на выходе образовательных систем используют исследование компьютерной и информационной грамотности ICILS (2013 год), сетевой готовности, оценки сайтов образовательных учреждений Webometrics $[9,10]$ и другие.

Замечания к существующим международным оценкам и показателям связаны с достоверностью мониторинга, интерпретацией результатов [11, 12]. В отношении национальных статистических систем авторы работы [11] говорят о несовершенстве существующей системы мониторинга и о возможных направлениях модификации существующей системы федерального статистического наблюдения сферы непрерывного профессионального образования посредством включения в существующую отчетность идентификаторов, позволяющих корреспондировать подготовку кадров с конкретным национальным проектом и, соответственно, с национальными проектами в целом. В нашем понимании, для оценки качества подготовки студентов необходимо учитывать не только экономические показатели и индикаторы цифровой экономики, но и целевые показатели глубины охвата цифровой инфраструктурой на местах.

\section{Цель исслеАования}

Изучить возможность оценки деятельности университетов на основе показателей цифровой инфраструктуры. Разработать группы квалиметрических индикаторов цифрового образования, при этом использовать характеристики ИКТ служб информатизации университета, а также оценить применяемость расчетно-статистических методов оценки к разработанным индикаторам.

\section{Материалы и результаты исслеАований}

В высшей школе информационные потребности возникают в контуре управления и обучения. В настоящее время происходит реструктуризация служб проректора по информационным технологиям, ее трансформация от централизованной к распределенной модели управления информационными ресурсами. Очевидно разделение функционала и зон ответственности по совокупности ИКТ, ресурсного, методического и информационного обеспечения, поскольку в штатном расписании большинства подразделений введены ставки программистов, инженеров, заведующих лабораториями, лаборантов, решающих вопросы IT сопровождения. Такие подразделения, по сути, становятся службами информатизации, при этом центры информационных технологий университета теряют сложившуюся историческую исключительность. Так, например, авторы работы [13] отмечают значимость научной библиотеки для совершенствования IT-ресурсов и сервисов, содействующих развитию информационной инфраструктуры университета. Авторы работы [14] отмечают, что одной из задач решаемых УМО (учебно-методический отдел) вуза является администрирование существующей информационно-образовательной среды (LMS), консультирование и техническая поддержка ППС вуза по проблемам, связанным с эксплуатированием LMS. По мнению [15] возрастает роль факультетов и кафедр, как основных подразделений университетского образования курирующих вопросы информационных технологий в образовательной среде.

К оценке информационно-цифровых индикаторов применяют подходы, основанные на оценке статистических показателей информационной среды - например [16], рейтинговые оценки - например бальные методики согласно источника [17], эконометрический анализ - например SCRUM-методологию оценки [18], комбинаторные методы - например методы оценки межотраслевого кластера [19] и другие.

Внешние показатели цифровой грамотности населения, коммуникативной грамотности, уровня создания цифрового контента, владения цифровой безопасностью, навыков решения проблем в цифровой среде описаны Федеральным проектом «Кадры для цифровой экономики» национальной программы «Цифровая экономика Российской Федерации» [20] и считаем недостаточными для обоснованного позиционирования точек роста университета, как объекта подготовки высококвалифицированных кадров для цифровой экономике. Внутренняя оценка показателей развития ИКТ университетов, как правило основана на системе менеджмента качества, мониторинге показателей насыщенности 


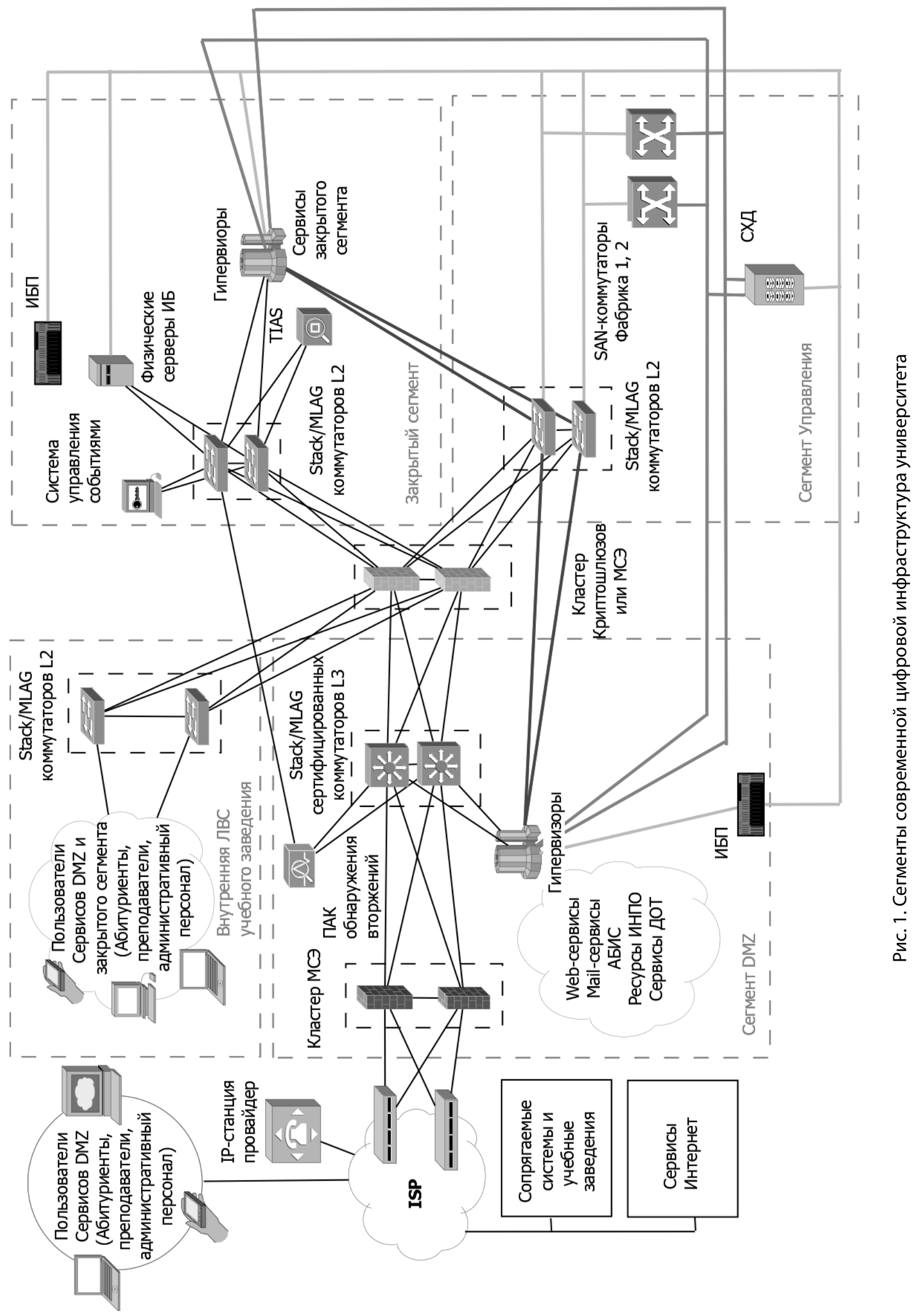


подключенных к Internet AРM (автоматизированных рабочих мест), количества лицензионного программного обеспечения, внутренних и внешних образовательных ресурсах, характеристик телекоммуникационных каналов связи с провайдером и также не дает полноценного ответа на вопросы оперативного и стратегического планирования цифровой инфраструктуры.

Предложенные квалиметрические группы индикаторов цифрового образования по предложенному определению службы информатизации университета считаем возможным использовать для самооценки качества подготовки кадров для цифровой экономике, для экспресс-диагностики образовательного процесса, корректировки плана инвестиций в ближайших и долгосрочных горизонтах планирования, для приведения к эквивалентным графическим представлениям данных аналитических агентств IDC, Bitkom Research GmbH, Gartner и Forrester, или форматах отображения результатов образовательного мониторинга ОЭСР. Индикаторы учитывают и сформированность сегментов современной цифровой инфраструктура университета, рис. 1: сервиса внешних пользователей DMZ (Demilitarized Zone - демилитаризованная зона), сопрягаемых информационных систем и учебных заведений; демилитаризованной зоны, сегмента внутренней ЛВС (локальной вычислительной сети; сегмента управления и закрытого сегмента.

Рассмотрим индикаторы службы проректора по информационным технологиям, учебно-методического отдела, научной библиотеки, института непрерывного профессионального образования (ИНПО), компьютерной безопасности выделенных в отдельные сегменты.

\section{Индикаторы службы проректора по информационным технологиям}

Служба проректора по информационным технологиям обеспечивает устойчивое функционирование инфраструктуры систем управления и образования 1/10 Gbit/s Ethernet и 1/10 Gbit/s Fibre Channel, администрирования части серверного оборудования и SAN-фабрик, программно-аппаратных средств защиты информационных ресурсов, IT сопровождения в зоне ответственности. Нами разработаны следующие индикаторы: отношение количества коммутаторов уровней L2, к общему числу сетевых АРМ; количество серверов (виртуальных, облачных) учебного процесса на факультетах, единиц; значение ежемесячного трафика кафедр к количеству ППС; отношение полосы пропускания «последней мили» к пропускной способности основного Internet-шлюза; количество вендоров в поле ИКТ университета, единиц; отношение количества подразделений службы проректора по информационным технологиям к числу информационно-технических служб; ежегодное количество научно-методических публикаций службы по тематикам «информатизация, цифровизация, ИКТ», к общему числу сотрудников службы проректора по о информационным технологиям; частота аудиторских проверок вычислительной и телекоммуникационной техники; вес показателей: «качество документирования стандартов университета по информатизации», «качество организации службы по информатизации», «условия труда», «качество труда специалистов по информатизации».

В качестве примера приведем смысловые характеристики индикатора «отношение количества коммутаторов уровней L2, к общему числу сетевых APM». Тождественность значения приведенного индикатора 1/24 означает преобладание в архитектурном решении стоечных коммутаторов, коммутационных узлов, выделенных серверных помещений и пулов, что является наиболее удобной формой осуществления централизованной маршрутиризации, балансировки нагрузки для тяжелых сетевых приложений. Уменьшение значения индикатора указывает на кросс-платформенное дробление телекоммуникационной инфраструктуры, низкую пропускную способность каналов связи, отсутствие стратегии масштабирования и общей идеологии построения телекоммуникационных сетей университета. Также возможно оценивать указанный индикатор в отношении PoE/PoE+ к Non-PoE.

\section{Индикаторы учебно-методического отдела}

УМО осуществляет организацию и управление учебным процессом, контроль обеспеченности дисциплин необходимыми учебными и учебно-методическими материалами, контроль образовательной деятельности обучающихся в соответствии с требованиями федеральных государственных образовательных стандартов, анализ ресурсного обеспечения, формирует статистику по трудоустройству и практике студентов, использует форсайт-технологии, администрирования частей LMS вуза. В период ограничений очного обучения по основаниям COVID19, УМO решает задачи апробирования экспериментальных моделей учебно-методической работы, виртуального присутствия ППС (профессорско-преподавательский состав) и контроля учебно-методического процесса, фактографической отчетной документации ДОТ и он-лайн. Коллегиально решаемые задачи динамичны по времени, поэтому цифровые ресурсы УМО требуют долгосрочного планирования, с использованием существующих баз данных и агрегаторов в аппаратном и программном сегментах ИКТ, что также учтено при создании линейки индикаторов цифрового образования УМО.

Для УМО разработаны следующие индикаторы: отношение количества мультимедийных лекционных 
аудиторий к количеству часов лекций-презентаций проведенных преподавателями в течение учебного года; отношение среднего количества часов загрузки компьютерных классов в день к общему количеству компьютерных классов; количество оперативных совещаний по вопросам IT, проводимых УМО в декаду, единиц; отношение количества электронных мультимедийных учебно-методических материалов разработанных ППС к количеству ППС; отношение количества интерактивных контрольно-измерительных материалов разработанных ППС к количеству ППС; количество используемых УМУ информационных систем, единиц.

Покажем значимость индикатора «отношение среднего количества часов загрузки компьютерных классов в день к общему количеству компьютерных классов». При планировании расписания необходимо понимать последовательность работы вспомогательного персонала компьютерных классах, которая складывается из ежедневной профилактики и настроек вычислительной техники согласно внутренних нормативных документов. Ежедневные мероприятия и внеплановые работы требуют ненормируемых с точки зрения учебного процесса затрат времени для их реализации. Таким образом, индикатор дает качественную оценку подготовки аудитории, оснащенной программно-техническими средствами, а также показывает достаточность или избыток учебных вычислительных мощностей и сетевой учебной периферии.

\section{Индикаторы научной библиотеки университета}

Сегодня университетскую библиотеку можно назвать информационно-исследовательским центром, требующим особого внимания к телекоммуникационной инфраструктуре, организуемой как правило по VPN-технологии и систем аппаратной виртуализации Hyper-V, к производительности серверного оборудования автоматизированных библиотечных информационных систем (АБИС), к объемам хранилищ, системам компьютерной безопасности АБИС работающим с удаленными TCP/IP запросами из неконтролируемой зоны к DMZ и внутренней контролируемой зоны в части RDP remote desk-top protocol и других сервисов. Научная библиотека выполняет функции аккумулятора научно-исследовательских работ, учебно-методической литературы, гуманитарной литературы и периодических изданий. В корпоративной сети университетов функционируют электронный каталог научной библиотеки и внешних интеграторов, дополнительные сервисы, в том числе на коммерческой основе.

Для научной библиотеки разработаны следующие индикаторы: отношение электронной документовыда- чи, тыс. ед. в год, к количеству студентов очной формы обучения; интеграция АБИС с внешними электронными отечественными и зарубежными ресурсами, единиц; отношение количества сотрудников информационного профиля научной библиотеки к количеству единиц вычислительной и периферийной техники научной библиотеки; количество электронных справочно-информационных баз данных доступных студентам и преподавателям.

Рассмотрим, например, индикатор «отношение электронной документовыдачи, тыс. ед. в год к количеству студентов очной формы обучения». Электронная книговыдача характеризует объем фондов, наличие высокоскоростной вычислительной сети научной библиотеки и высокопроизводительного сервера АБИС, каналообразующего оборудования. Числовое значение индикатора позволяет судить о рациональности капиталовложений в аппаратные и программно-технические мощности, степень вовлеченности студентов в ресурсное обеспечение учебных дисциплин.

\section{Индикаторы института непрерывного профессионального образования}

Общее направление деятельности института заключается в оказании образовательных услуг профессиональной переподготовки, повышения квалификации различных возрастных групп, организация консультационных услуг и репетиторства, дополнительного образования, профориентация школьников, в том числе на основе стандартов WorldSkills Russia. Подготовка и переподготовка осуществляется по программам среднего профессионального образования (СПО), высшего образования (ВО), дополнительного образования (ДО).

Для ИНПО считаем необходимым применение следующих индикаторов: количество ЭУМК в базах данных систем дистанционного обучения по программам СПО, ВО, ДО к общему числу лицензированных образовательных программ; качество информативного содержания размещенного на официальных Internet-источниках (социальных сетях); количество образовательных серверов ИНПО (сервисов, электронных баз данных), единиц; используемые и предоставляемые сервисы laaS и SaaS, единиц.

Рассмотрим в качестве примера индикатор «количество образовательных серверов ИНПО». В рамках оказания образовательных услуг дистанционное обучение на основе конвергентных IP услуг и web, предполагает высокоскоростной доступ к дисковым хранилищам и массивам контента образовательных услуг, дисковому пространству на базе SAN-фабрик университета. Индикатор характеризует наличие зонирования для ауди- 
о-визуальных и гипертекстовых дистанционных образовательных материалов, графических САПР.

\section{Индикаторы компьютерной безопасности}

Определены с целью оценки безопасности сетевых ресурсов университета к угрозам несанкционированного доступа, перехвата и изменения легитимного трафика, нештатного использования телекоммуникационной инфраструктуры и официальных сетевых источников, а также с целью определения избыточности подключения к сети Internet с точки зрения кластерной инфраструктуры. Установлены следующие индикаторы: отношение количества объектов демилитаризованной зоны, к суммарному количеству внешних запросов; количество внешних каналов связи ISP (Internet Service Provider), единиц; количество лицензионных аппаратно-программных межсетевых экранов (МСЭ), в том числе ПАК (программно-аппаратных комплексов) обнаружения вторжений, единиц; количество прецедентов нарушения категорий информационной безопасности, единиц в год; количество внутренней распорядительной документации по методологии защиты информационных ресурсов университета и методик действия в чрезвычайных ситуациях, единиц; количество выявленных фактов нарушения 152 Ф3 «О защите персональных данных» на официальных Internet ресурсах университета и социальных сетях.

Например, значение индикатора «отношение количества объектов демилитаризованной зоны, к суммарному количеству внешних запросов» позволяет оценить угрозы безопасности коллективной работы сотрудников и обучающихся, в части сервисов mail, web, ftp, ХMPР и других, а также предварительно оценить затраты на обеспечение защиты конфигураций, вложения в RAID-системы дисковых массивов или иных систем и технологий репликации данных в даннм сегменте.
Нами апробированы графические и расчетно-статистические методы оценки индикаторов. Сделано заключение о возможности применения графических и расчетно-статистических методов. На основании проведенных исследований отмечаем: индикаторы цифрового образования условно подразделяются на стационарные и динамические; оценка индикаторов возможна методами сравнения средних, сравнения дисперсий, регрессионного анализа, корреляционного анализа только при наличии статистического ряда; метод априорного ранжирования является универсальным методом оценки; индикаторы можно условно подразделить на индикаторы количественной и качественной оценки, для количественной оценки подходят как графические, так и расчетно-статистические методы, для качественной - метод априорного ранжирования.

\section{Зак^ючение}

В целевых показателях мониторинга российской высшей школы отсутствуют инфраструктурные показатели цифровизации.

Индикаторы цифрового образования - необходимый компонент оперативного планирования и оценки перспектив развития высшего учебного заведения.

К индикаторам цифрового образования возможно применение статистических, расчетно-статистических методов оценки.

И в заключении, можно утверждать о возможности создания биллинговой системы оценки качества образования для организаций высшего образования, блиц проверки государственных ИТ и ИС систем, выпуска аналитических сводок и отчетов с учетом общемировых тенденций развития ИКТ на основе индикаторов цифрового образования служб информатизации.

\section{ЛИТЕРАТУРА}

1. Индикаторы цифровой экономики: 2019: статистический сборник / Г.И. Абдрахманова, К.0. Вишневский, Л.М. Гохберг и др.; Нац. исслед. ун-т «Высшая школа экономики».—- М.: НИУ ВШЭ, 2019.-248с.

2. Образование в цифрах: 2019: краткий статистический сборник / Н.В. Бондаренко, Л.М. Гохберг, Н.В. Ковалева и др.; Нац. исслед. ун-т «Высшая школа экономики».— М.: НИУ ВШЭ, 2019.— 96 с.

3. Постановление Правительства РФ от 5 мая 2016 г. № 392 «0 приоритетных направлениях использования и развития информационно-коммуникационных технологий в федеральных органах исполнительной власти и органах управления государственными внебюджетными фондами и о внесении изменений в некоторые акты Правительства Российской Федерации».

4. Брякина А.В., Сироткина Н.В. Последовательность принятия стратегических управленческих решений на основе индикаторов управления//Территория науки. — 2014. — № 6. - С. 141-147.

5. Челнокова 0.Ю. Индикаторы оценки эффективности функционирования региональных систем высшего образования //Известия Саратовского университета. Новая серия. Серия Экономика. Управление. Право. — 2019. Т. 19, вып. 4. — C. 409-414.

6. Вальдман И.А. Сравнительный анализ опыта использования результатов национальных мониторингов учебных достижений в Австралии, США и Чили// Проблемы современного образования.— 2015.— № 1.— С. 5-28. 
7. Писарева Л.В. Технология исследования качества образования и индикаторы уровня его развития (ИРО, ИРЧП)//Проблемы современного образования. - 2017. - № 3.- С. 52-63.

8. Агранович М.Л., Ермачкова Ю.В., Селиверстова И.В. Российское образование в контексте международных индикаторов, 2019. Аналитический доклад / Агранович М.Л., Ермачкова Ю.В., Селиверстова И.В.— М.: Центр статистики и мониторинга образования ФИРО РАНХиГС, 2019. — 96 с.

9. Шевченко Д.А., Локтюшена Ю.В. Рейтинг Webometrics: индикатор качества и конкурентоспособности российских университетов на мировом рынке образовательных услуг//Вестник РГГУ. Серия «Экономика. Управление. Право».— 2016. — № 2 (4). — C. 95-102.

10. Nwohiri A.M., Pechnikov A.A. Application of webometrics methods for analysis and enhancement of academic site structure based on page value criterion//Bectник Санкт-Петербургского университета. Прикладная математика. Информатика. Процессы управления.— 2019.— № 3.— С. $337-352$.

11. Федотов А.В., Лебедев К.В., Коваленко А.А., Полушкина А.О. Национальные проекты и совершенствование мониторинга их реализации в сфере непрерывного профессионального образования//Образовательная политика.— 2020.— № 1.—C. 28-43.

12. Платонова Е.Д., Мусарский М.М. Всемирное движение за образование для всех как фактор развития мировой экономики//Экономический журнал.2018. — № 3.- С. 108-120.

13. Плотникова Н., Струков Е, Вагнер К. Повышение уровня научно-исследовательской деятельности профессорско-преподавательского состава в условиях формирования конкурентоспособности вуза//Филология и культура.— 2019.— № 2. - С. 285-290.

14. Захарова И.И., Мезеветова Н.С., Филипсон С.К. Особенности проектирования информационной системы управления учебно-методическими процессами университета//Вестник Пермского национального исследовательского политехнического университета. Электротехника, информационные технологии, системы управления.— 2018.— № 27.- С. 209-225.

15. Зуфарова А.С. Роль информационных технологий в образовательном процессе//Управление образованием: теория и практика.— 2020.— № 3.C. $105-112$.

16. Сальников В.А., Азаров В.Г. Проблема управления информатизацией в высшей школе и пути ее решения//Информационно-управляющие системы.2009.— № 2.- - . 70-74.

17. Башин Ю.Б., Борисова К.Б. К вопросу об экономической оценке информатизации бизнеса//Экономика и бизнес: теория и практика. 一 2020.—№ 5-1. C. 73-78.

18. Шапошников В.Л., Артамкин А.С., Хорошун К.В. Модель диагностики информатизации предприятия для критериальной оценки ее уровня//Вестник Российского университета кооперации. - 2018. — № 1.— С. 84-90.

19. Кадцына Е.С. Концептуальная модель оценки и оптимизации развития процесса региональной информатизации//Вестник Российского экономического университета им. Г.В. Плеханова

20. Приказ Минэкономразвития России от 24 января 2020 г. № 41 «0б утверждении методик расчета показателей федерального проекта «Кадры для цифровой экономики национальной программы «Цифровая экономика Российской Федерации».

(c) Азаров Вячеслав Геннадьевич (west_55@inbox.ru)).

Журнал «Современная наука: актуальные проблемы теории и практики»

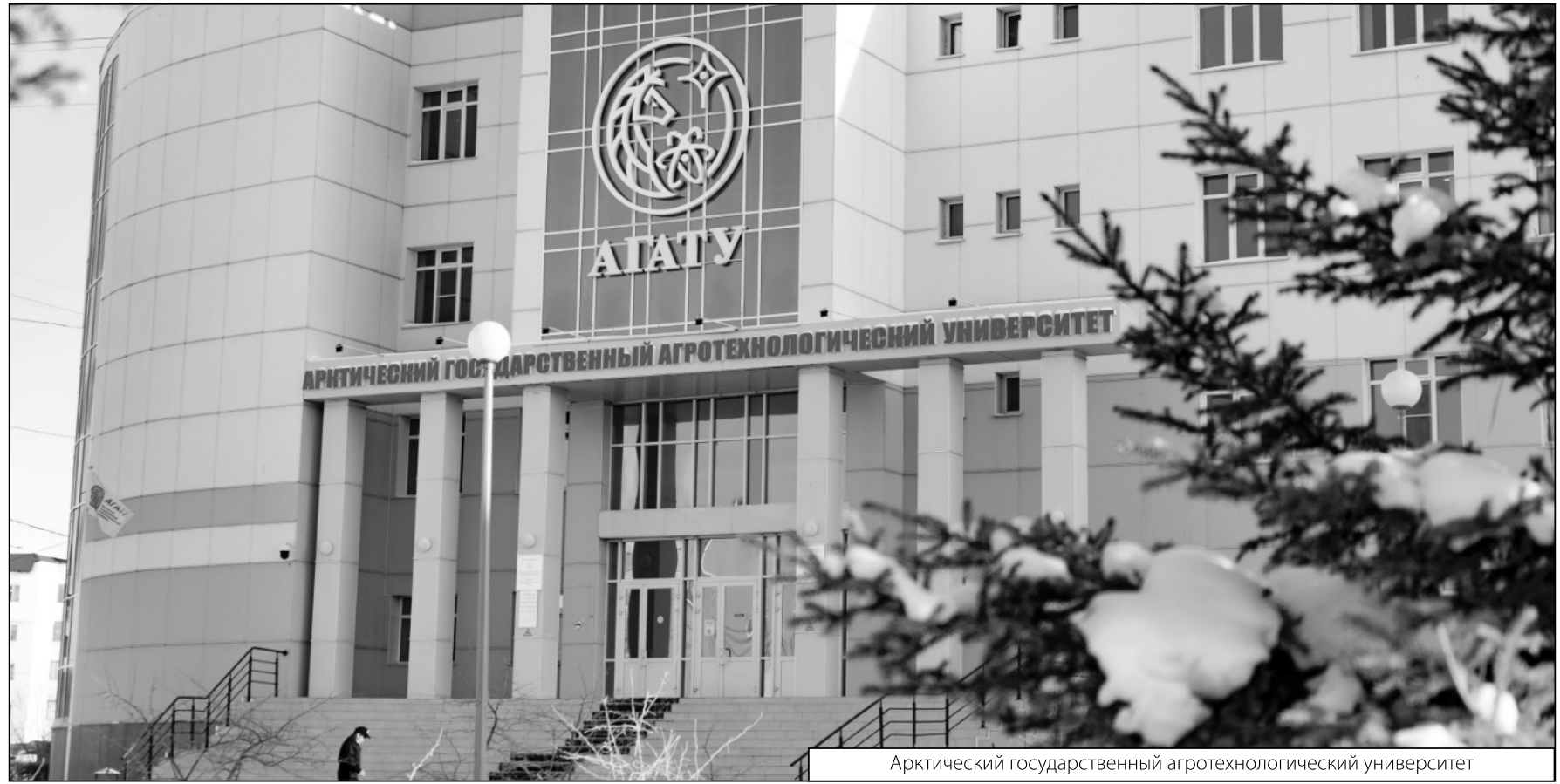

